\title{
Besserstellung der Haus- und Kinderärzte
}

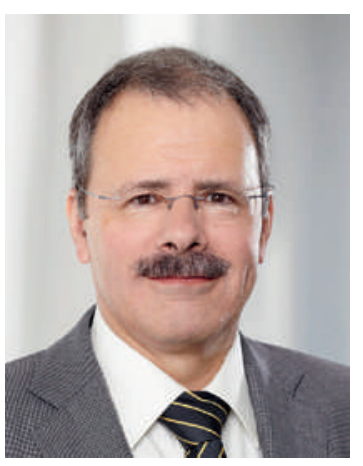

Nach langen Jahren des Rückschritts haben die Haus- und Kinderärztinnen und -ärzte eine Besserstellung erreicht: Mit der Unterstützung von Bundesrat Alain Berset und der FMH soll u.a. ihr Einkommen um gesamthaft 200 Millionen Franken pro Jahr angehoben werden. Auslöser und kraftvoller Treiber dieses Fortschrittes war die Volksinitiative «Ja zur Hausarztmedizin». Ohne sie wären wir heute kaum da, wo wir jetzt sind. Ihre Lancierung im Jahr 2010 führte zum bundesrätlichen Masterplan und damit zu einer Stärkung der Haus- und Kinderärzte.

\section{Kann auch die FMH zufrieden sein?}

Für die FMH ist das Scheitern der Verhandlungen mit den Tarifpartnern eine verpasste Chance. Es bleibt vorläufig offen, wie die von allen Tarifpartnern unterstützte Besserstellung der Haus- und Kinderarztmedizin oder Haus- und Kinderärzte kostenneutral finanziert werden soll.

Belasten wird die verpasste Tarifvereinbarung zur Finanzierung der Besserstellung der Haus- und Kinderärzte die ganze Ärzteschaft. Denn nun droht ein isolierter Eingriff des Bundesrates in den ambulanten Arzttarif mit Umverteilung von Spezialisten zu den Grundversorgern. Die FMH zweifelt, ob dieser Eingriff wie vom KVG gefordert - sachgerecht und betriebswirtschaftlich ausgewogen erfolgen kann.

Für die FMH ist die vom Bundesrat eingeforderte kostenneutrale Umsetzung der Besserstellung über die Tarifstruktur TARMED wenig verständlich. Vergessen wir nicht: Es waren die

\section{Punktuelle, isolierte Eingriffe in die Tarifstruktur führen zu Ungleichheit. Nur eine Gesamtrevision ermöglicht eine sachgerechte und betriebswirtschaftlich korrekte Tarifierung.}

Die FMH begrüsst diese Besserstellung. Wir anerkennen auch die Besonnenheit, das politische Augenmass und die Bescheidenheit, die das Initiativkomitee mit dem Rückzug der Volksinitiative beweist. Gefordert wurde ursprünglich eine Besserstellung um 350 Millionen Franken pro Jahr; zugesichert hat der Bundesrat 200 Millionen Franken. Genommen hat der Bundesrat den Haus- und Kinderärzten seit 2009 pro Jahr 80 Millionen Franken, durch Abwertung des Labortarifs; geben wird er ihnen ab 2014 durch Aufwertung des Labortarifs bloss zusätzliche 35 Millionen Franken pro Jahr.

\section{Die Volksinitiative «Ja zur Hausarztmedizin» war treibende Kraft und führte zu einer Stärkung der Haus- und Kinderärzte.}

\footnotetext{
Der Bundesrat kann zufrieden sein.

Mit dem Masterplan vermag er erstens die Haus- und Kinderärztinnen kostengünstig besserzustellen. Zweitens hat er die für ihn schwierige Volksinitiative «Ja zur Hausarztmedizin» vom Tisch. Und drittens kann er erstmals direkten Einfluss auf den ambulanten Arzttarif TARMED nehmen.
}

damalige «kostenneutrale Einführung» des ambulanten Arzttarifs TARMED und zusätzliche Eingriffe des Preisüberwachers, die zum heutigen Ungleichgewicht zu Lasten der Haus- und Kinderarztmedizin oder Haus- und Kinderärzte führten. Die FMH bezweifelt, dass der Bundesrat seine strategische Forderung nach vermehrter Ausrichtung der Versorgung von stationärer Akut- auf ambulante Langzeitversorgung [1] ebenso kostenneutral umsetzen kann. Ohne Mehrinvestitionen im gesamten ambulanten Sektor und damit in die Zukunft der medizinischen Versorgung wird dies kaum funktionieren.

Die FMH will eine sachgerechte und betriebswirtschaftlich korrekte Tarifierung aller ärztlichen Leistungen, wie dies das KVG ausdrücklich verlangt. Dazu arbeitet sie zusammen mit $\mathrm{H}+$ und der Medizinaltarif-Kommission MTK seit Anfang 2012 intensiv an der Gesamtrevision der Tarifstruktur TARMED. Die neue Struktur wird zu einer sachgerechteren Abbildung aller ärztlichen Leistungen führen - auch derjenigen der Haus- und Kinderärzte. Die FMH wird alles daransetzen, die Tarifrevision TARMED trotz isoliertem bundesrätlichen Tarifeingriff mit ihren Tarifpartnern unbeirrt fortzuführen und bis Ende 2015 abzuschliessen.

Dr. med. Jürg Schlup, Präsident der FMH

1 Gesundheit2020: Die gesundheitspolitischen Prioritäten des Bundesrates. Publiziert. Bern, 16. Januar 2013. S. 2. 